\title{
Household food insecurity and dietary intake in Korea: results from the 2012 Korea National Health and Nutrition Examination Survey
}

\author{
Hyun Ja Kim and Kyungwon Oh* \\ Division of Health and Nutrition Survey, Korea Centers for Disease Control and Prevention, 187 Osongsaengmyeong2-ro, \\ Osong-eup, Heungdeok-gu, Cheongiu-si, Chungcheongbuk-do 361-951, Republic of Korea
}

Submitted 17 October 2014: Final revision received 23 January 2015: Accepted 16 February 2015: First published online 1 April 2015

\begin{abstract}
Objective: To examine the prevalence of household food insecurity and compare dietary intake by food security status in a representative Korean population. Design: Cross-sectional. Food security status of households was classified using an eighteen-item food security questionnaire. The nutrition survey comprised questions on dietary habits, a $24 \mathrm{~h}$ dietary recall and a semi-quantitative FFQ. Setting: The 2012 Korea National Health and Nutrition Examination Survey. Subjects: A total of 3007 households completed the food security questionnaire. Family members within each household aged $\geq 1$ year $(n 7118)$ participated in the nutrition survey.

Results: Results from the 2012 survey indicated that $88.7 \%$ of Korean households showed food security. The remaining $11.3 \%$ (9.3\% for food insecurity without hunger and $2.0 \%$ for food insecurity with hunger) were in food-insecure households. The prevalence of household food insecurity was $13 \cdot 2 \%$ in households with children and $10.3 \%$ in households without children. Mean daily intakes of energy, fat and carbohydrates were not significantly different between food-secure and food-insecure adults. In contrast, mean daily intakes of protein, crude fibre, vitamins and minerals as well as weekly consumption frequencies of vegetables, seaweeds, fruits, fruit juice, nuts, and milk and milk products were significantly lower in food-insecure adults compared with food-secure adults. Conclusions: The study demonstrated that food insecurity is associated with reduced intakes of healthy foods and nutrients essential for health and growth in a representative Korean population.
\end{abstract}

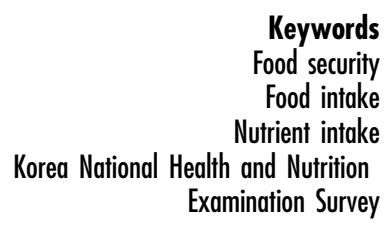

Food insecurity is defined as limited availability of nutritionally adequate and safe foods or the lack of ability to acquire acceptable foods in a socially acceptable ways ${ }^{(1)}$. In South Korea, national food availability and the purchasing power of Koreans have been enhanced by rapid economic growth $^{(2)}$. However, differences in the quantity and quality of dietary intake based on socio-economic status have widened over time ${ }^{(3)}$. Even though a Western-style diet has become popular due to the rapid socio-economic changes and Westernization in Korea, the typical Korean diet is still considered a healthy diet composed of white rice, various vegetables in fresh, cooked and pickled form, and low in fat $^{(2)}$. However, socio-economic inequality and inaccessibility to adequate nutrition increase the intake of unhealthy foods $^{(4)}$ as well as hunger, which may contribute to health inequalities. In order to develop strategies or programmes to assist vulnerable individuals with food insecurity, the prevalence of people with food insecurity first needs to be identified using a validated questionnaire among a representative sample of the Korean population and then their dietary intake should be evaluated through comparison with the population who have food security. However, previous studies on food insecurity in South Korea were conducted in socially disadvantaged classes or in a rural area ${ }^{(5-8)}$.

Since 2005, surveys on household food insecurity have been conducted using a single-item questionnaire to detect food insufficiency in the Korea National Health and Nutrition Examination Survey (KNHANES). However, this specific parameter was limited to estimating food insufficiency due to poverty. Therefore, it has been difficult to ascertain whether households have problems in terms of accessibility to and availability of foods and to what extent of these problems exist ${ }^{(1)}$. In order to estimate all aspects of food availability, accessibility and utilization, an 
eighteen-item questionnaire on household food security was introduced in the 2012 KNHANES.

The present study aimed to examine the extent and severity of household food insecurity in a representative Korean population and to certify which characteristics of the household and householder affect food insecurity. Furthermore, we identified whether dietary intake of household members differs by the status of food security using data from the 2012 KNHANES.

\section{Methods}

\section{Study population}

The KNHANES is a nationwide cross-sectional survey initiated in 1998 for examining the health and nutritional status of the non-institutionalized Korean population. The survey was conducted as a tri-annual survey in 2001 and 2005. Since 2007, it was converted to an annual survey and conducted by the Korea Centers for Disease Control and Prevention. The present study was based on data from the 2012 KNHANES. In the 2012 KNHANES, 3840 representative households of non-institutionalized Korean citizens residing in Korea were selected using a stratified and multistage clustered probability sampling method. Among 3254 households that participated in the health interview, examination and nutrition survey, a total of 3043 households completed the food security questionnaire. Thirtysix households that were missing data on one or more item (s) of the food security questionnaire were excluded. Finally, 3007 households and their 7118 family members aged $\geq 1$ year in the selected households were included in the current analysis.

All procedures and protocols used in the study were approved by the institutional review board of the Korea Centers for Disease Control and Prevention (201201EXP-01-2C). Written informed consent regarding the survey was obtained from all participants.

\section{Data collection}

Health interview and examination

The health interview and examination were performed by trained medical staff and interviewers in mobile examination centres. The health interview provided detailed information on household characteristics (e.g. household type, household income, housing ownership, receipt of basic livelihood security, residential location) and family members' sociodemographic features (e.g. sex, age, education, marital status), receipt of food assistance, healthrelated behaviours (e.g. smoking, drinking) and general health status.

\section{Nutrition survey}

The nutrition survey consisted of dietary habits and a $24 \mathrm{~h}$ dietary recall for all family members aged $\geq 1$ year and a semi-quantitative FFQ for adults aged 19-64 years. The nutrition survey was conducted by trained dietitians in the homes of participants. The semi-quantitative FFQ identified the consumption frequency and amount for 112 food items over a 1 -year period prior to the interview ${ }^{(9)}$. Daily energy and nutrient intakes from the $24 \mathrm{~h}$ dietary recall and semi-quantitative FFQ were estimated using the Korean Foods and Nutrients Database of the Rural Development Administration ${ }^{(10,11)}$. The validity and reproducibility of the semi-quantitative FFQ have been described in detail elsewhere ${ }^{(12)}$. We used data from the FFQ to compare food and nutrient intakes between foodsecure adults and food-insecure adults because the reference period of the FFQ was same as that of the food security questionnaire; moreover, FFQ data represented the usual intake. To estimate the proportions of energy intake deficiency (i.e. energy intake less than $75 \%$ of the estimated energy requirement) and nutrient intake deficiency (i.e. nutrient intake less than the estimated average requirement) by age and $\operatorname{sex}^{(13)}$, the absolute intakes of energy and nutrients from a $24 \mathrm{~h}$ dietary recall were used for all family members aged $\geq 1$ year.

\section{Housebold food security}

The food security questionnaire developed by the Korea Centers for Disease Control and Prevention was based on the eighteen-item US Household Food Security Survey Module (HFSSM). The household food security questionnaire consisted of three questions on household food conditions and seven questions for adults. In cases of households with children, an additional eight questions for children were administered. Each question specified the food condition due to the lack of money to buy food during 1 year prior to the interview. A detailed description concerning the development and validation of this index has been published elsewhere ${ }^{(7,14)}$. In brief, as a result of the validity and reliability study conducted in 446 households, the eighteen-item questionnaire had good internal consistency (Cronbach's $\alpha=0 \cdot 85$ ) and construct validity by showing the parallels between the response curves of food insecurity severity and household income level. Also, criterion-related validity was confirmed by the significant relationship between food insecurity status and characteristics of the household or householder, such as socioeconomic status, health status and dietary diversity. In the current study, Cronbach's $\alpha$ for internal consistency was 0.85 and internal consistency ranged from 0.83 to 0.86 after eliminating each item.

The questionnaire was administered to the predominant food purchaser in each household. To classify the household food security status, a score of 1 for affirmative responses indicating food-insecure conditions (e.g. 'often' or 'sometimes', 'almost every month' or 'some months but not every month' and 'yes') or a score of 0 for all other responses was given to each question and then a summative score was calculated. Households were classified 
into a food-secure group if the total score was $\leq 2$ and a food-insecure group if the total score was $\geq 3$. Foodinsecure households were further classified into three groups according to the severity of food insecurity as follows: food-insecure without hunger (score of 3-5), moderate food-insecure with hunger (score of 6-8) and severe food-insecure with hunger (score of 9-10) for households without children; and food-insecure without hunger (score of 3-7), moderate food-insecure with hunger (score of 8-12) and severe food-insecure with hunger (score of 13-18) for households with children. There were few households classified as severe food-insecure. Therefore, moderate or severe food-insecure households were placed into the single category of 'food-insecure households with hunger'. The status of food security of all family members within a household was classified by food security status of the household.

\section{Statistical analysis}

Energy-adjusted nutrient values were obtained using the residual method ${ }^{(15)}$. To improve the normality of the skewed distributions of nutrient intake and to create residuals of nutrient intake with a more constant variance across levels of energy intake, the values of nutrient intake were log-transformed prior to adjustment of energy intake. All analyses were conducted using the SAS 'proc survey' procedure (in the statistical software package SAS version 9.4) for analysing complex sample survey data. To represent the Korean population, sampling weights assigned to households or participants were applied to all analyses. Sampling weights were generated by considering the complex sample design, non-response rate of the target population and post-stratification. Data are presented as percentages with their standard errors for categorical variables and as means with their standard errors for continuous variables. Significant differences between the food-secure and food-insecure groups were tested using multivariate linear regression ('proc surveyreg') for weighted means and the $\chi^{2}$ test ('proc surveyfreq') and multivariate binary or multinomial logistic regression ('proc surveylogistic') for percentages after adjusting for age and sex. $P$ values $<0.05$ were considered statistically significant.

\section{Results}

In the 2012 KNHANES, the estimated percentage of households with food security was $88.7 \%$. The remaining $11.3 \%$ showed food insecurity $(9.3 \%$ for food insecurity without hunger and $2.0 \%$ for food insecurity with hunger). The prevalence of food-insecure households in households with children was $13 \cdot 2 \%$, which was higher compared with $10.3 \%$ in households without children. Of elderly participants living in a household with children, $21.6 \%$ were in a food-insecure condition (Table 1).

General characteristics of households and householders according to food security status are shown in Table 2. Food-insecure households had a higher proportion of a single householder (28.5\%), lone parent (14.9\%) and

Table 1 Prevalence of household food security and insecurity in the 2012 Korea National Health and Nutrition Examination Survey

\begin{tabular}{|c|c|c|c|c|c|c|}
\hline \multirow[b]{2}{*}{ Food security status $†$} & \multicolumn{2}{|c|}{ All } & \multicolumn{2}{|c|}{ Household without children } & \multicolumn{2}{|c|}{ Household with childrer } \\
\hline & $n$ & $\% *$ & $n$ & $\% *$ & $n$ & $\% *$ \\
\hline Households $(n)$ & \multicolumn{2}{|c|}{3007} & \multicolumn{2}{|c|}{1955} & \multicolumn{2}{|c|}{1052} \\
\hline Food-secure & 2722 & 88.7 & 1779 & 89.7 & 943 & $86 \cdot 8$ \\
\hline Food-insecure without hunger & 239 & $9 \cdot 3$ & 143 & $8 \cdot 4$ & 96 & $11 \cdot 2$ \\
\hline Food-insecure with hunger & 46 & $2 \cdot 0$ & 33 & 1.9 & 13 & $2 \cdot 0$ \\
\hline \multicolumn{7}{|l|}{ All individuals $\ddagger(n)$} \\
\hline Total & \multicolumn{2}{|c|}{7118} & \multicolumn{2}{|c|}{3580} & \multicolumn{2}{|c|}{3538} \\
\hline Food-secure & 6491 & 90.1 & 3302 & $92 \cdot 0$ & 3189 & $88 \cdot 3$ \\
\hline Food-insecure without hunger & 546 & 8.7 & 238 & $7 \cdot 0$ & 308 & $10 \cdot 2$ \\
\hline Food-insecure with hunger & 81 & 1.2 & 40 & 1.0 & 41 & 1.5 \\
\hline Children $(\leq 18$ years; $n)$ & \multicolumn{2}{|c|}{1618} & \multicolumn{2}{|c|}{ - } & \multicolumn{2}{|c|}{1618} \\
\hline Food-secure & 1450 & 86.5 & & & 1450 & 86.5 \\
\hline Food-insecure without hunger & 147 & 11.9 & & & 147 & 11.9 \\
\hline Food-insecure with hunger & 21 & 1.6 & & & 21 & 1.6 \\
\hline Adults (19-64 years; $n$ ) & \multicolumn{2}{|c|}{3949} & \multicolumn{2}{|c|}{2214} & \multicolumn{2}{|c|}{1735} \\
\hline Food-secure & 3675 & 91.8 & 2086 & 93.2 & 1589 & $90 \cdot 0$ \\
\hline Food-insecure without hunger & 245 & $7 \cdot 3$ & 115 & $6 \cdot 2$ & 130 & 8.7 \\
\hline Food-insecure with hunger & 29 & 0.9 & 13 & 0.6 & 16 & 1.3 \\
\hline Elderly $(\geq 65$ years; $n)$ & \multicolumn{2}{|c|}{1551} & \multicolumn{2}{|c|}{1366} & \multicolumn{2}{|c|}{185} \\
\hline Food-secure & 1366 & 86.7 & 1216 & 87.9 & 150 & 78.4 \\
\hline Food-insecure without hunger & 154 & $11 \cdot 0$ & 123 & 9.8 & 31 & $19 \cdot 0$ \\
\hline Food-insecure with hunger & 31 & $2 \cdot 3$ & 27 & $2 \cdot 3$ & 4 & $2 \cdot 6$ \\
\hline
\end{tabular}

*All percentages were calculated by applying sampling weights assigned to households or individual participants in the nutrition survey.

†Food security status was classified into three groups: food-secure (score $\leq 2$ ), food-insecure without hunger (score of 3-5 for households without children and score of 3-7 for households with children) and food-insecure with hunger (score $\geq 6$ for households without children and score $\geq 8$ for households with children). $\ddagger$ Classified by food security status of households. 


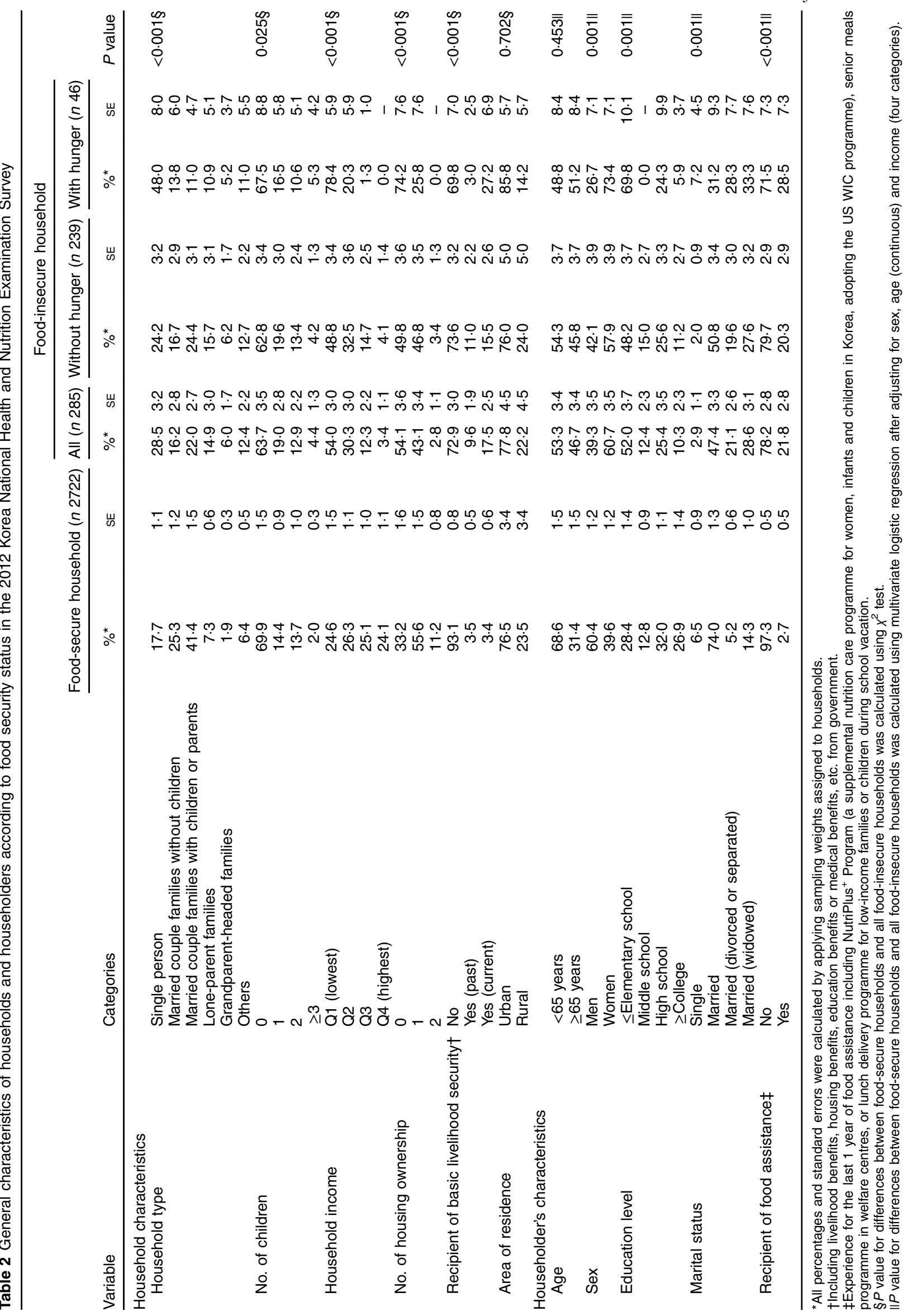


grandparent-headed families (6.0\%) compared with foodsecure households. Furthermore, more than half of the food-insecure households reported the lowest household income and were not homeowners. The proportion of current recipients of basic livelihood security was $17.5 \%$ for food-insecure households $(15.5 \%$ for food-insecure households without hunger and $27 \cdot 2 \%$ for food-insecure households with hunger), which was significantly higher compared with $3.4 \%$ for food-secure households. With respect to householder's characteristics, the proportion of elderly people aged $\geq 65$ years $(46.7 \%)$ and women $(60.7 \%)$ was significantly higher in food-insecure households. Additionally, after adjusting for sex, age and income of the householder, education level was significantly lower and the proportions of divorced, separated and widowed and food assistance recipients for last 1 year were significantly higher in food-insecure households compared with food-secure households.

Table 3 shows that the proportion skipping breakfast for last two consecutive days was significantly higher in children of food-insecure households (13.2\%) compared with children of food-secure households (8.1\%). The proportion of skipping three or more of any meals for $2 \mathrm{~d}$ was significantly higher in children $(5.8 \%)$ and adults (5.4\%) of food-insecure households compared with children (1.9\%) and adults (2.2\%) of food-secure households.

The mean weekly food consumption frequencies obtained from FFQ data for adults aged 19-64 years according to their food security status are shown in Table 4. Weekly consumption frequencies of all types of vegetables (fresh, cooked and pickled), seaweeds, fruits, fruit juice, nuts, and milk and milk products were significantly lower in food-insecure adults compared with food-secure adults, especially in adults of food-insecure households with hunger.

Table 5 shows the mean daily intakes of energy and nutrients from FFQ data in adults aged 19-64 years according to food security status. Mean intakes of energy, fat and carbohydrates were not significantly different between food-secure and food-insecure adults. In contrast, daily intakes of protein, crude fibre, minerals $(\mathrm{Ca}, \mathrm{P}$, $\mathrm{Na}, \mathrm{K}, \mathrm{Fe}$ ) and vitamins (vitamin $\mathrm{A}$, thiamin, riboflavin, niacin, vitamin C) were significantly lower in adults of food-insecure households compared with adults of foodsecure households, especially in adults of food-insecure households with hunger.

Figure 1 shows the prevalence of energy and nutrient deficiencies compared with the estimated energy requirement or the estimated average requirement among family members aged $\geq 1$ year using data from a $24 \mathrm{~h}$ dietary recall. The proportions of deficient intake of energy, protein, $\mathrm{Ca}, \mathrm{P}, \mathrm{Fe}$, vitamin $\mathrm{A}$, thiamin, riboflavin, niacin and vitamin $\mathrm{C}$ were significantly higher in family members of food-insecure households compared with family members of food-secure households.

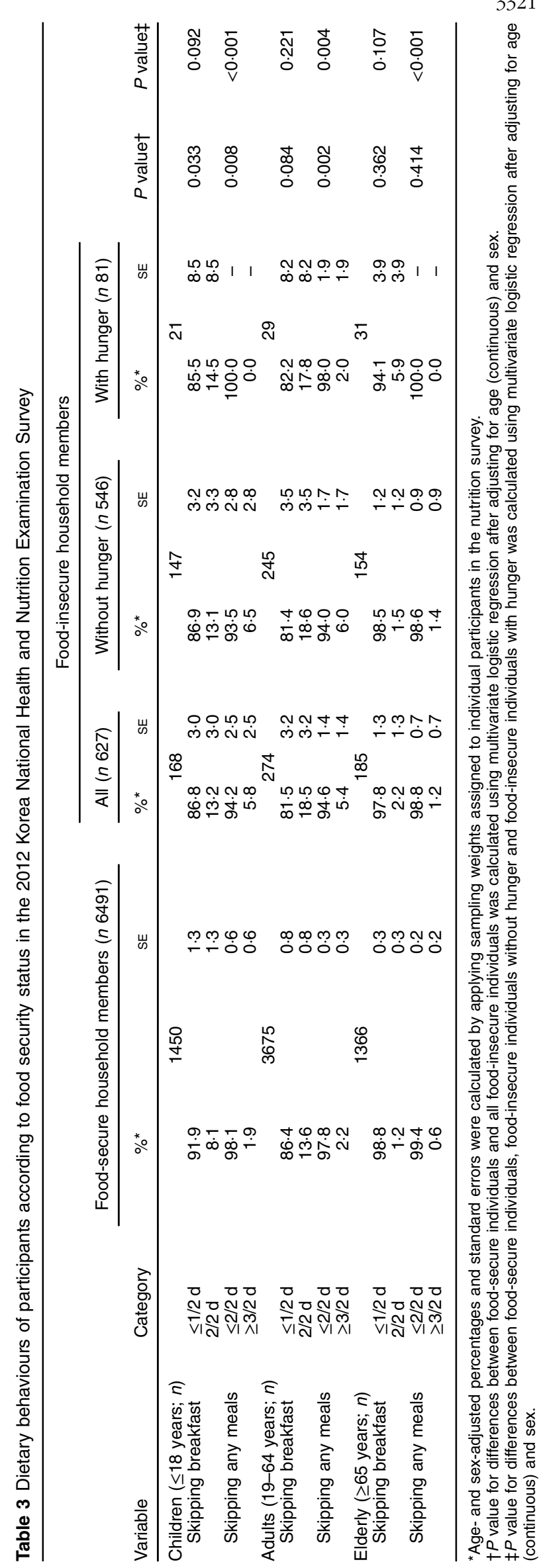


Table 4 Weekly food consumption frequencies obtained from the FFQ according to food security status among adults aged 19-64 years in the 2012 Korea National Health and Nutrition Examination Survey

\begin{tabular}{|c|c|c|c|c|c|c|c|c|c|c|}
\hline \multirow[b]{3}{*}{ Food group } & & & \multicolumn{6}{|c|}{ Food-insecure household adults } & \multirow[b]{3}{*}{$P$ value $\dagger$} & \multirow[b]{3}{*}{$P$ value $\neq$} \\
\hline & \multicolumn{2}{|c|}{$\begin{array}{l}\text { Food-secure household } \\
\text { adults }(n 3480)\end{array}$} & \multicolumn{2}{|c|}{ All $(n$ 261) } & \multicolumn{2}{|c|}{$\begin{array}{l}\text { Without hunger } \\
\qquad(n 233)\end{array}$} & \multicolumn{2}{|c|}{$\begin{array}{l}\text { With hunger } \\
\quad(n \text { 28) }\end{array}$} & & \\
\hline & Mean* & $\mathrm{SE}$ & Mean* & SE & Mean* & SE & Mean* & SE & & \\
\hline Cereals and cereal products & 23.6 & 0.2 & 24.4 & 0.6 & 24.5 & 0.6 & 23.4 & 1.7 & 0.186 & 0.354 \\
\hline Cooked rice & 17.9 & $0 \cdot 1$ & $18 \cdot 6$ & 0.4 & $18 \cdot 6$ & 0.4 & 18.5 & 1.3 & 0.133 & 0.317 \\
\hline Noodles & 2.4 & $0 \cdot 1$ & $2 \cdot 6$ & 0.1 & 2.6 & 0.1 & 2.5 & 0.5 & 0.160 & 0.317 \\
\hline Potatoes and corn & 1.2 & 0.0 & $1 \cdot 1$ & 0.1 & $1 \cdot 1$ & 0.1 & 1.2 & 0.5 & 0.397 & 0.682 \\
\hline Breads & $0 . \overline{9}$ & 0.0 & 1.2 & 0.2 & 1.2 & 0.2 & $0 . \overline{6}$ & 0.2 & 0.174 & 0.085 \\
\hline Pizza, hamburger, and sandwich & 0.4 & 0.0 & 0.4 & 0.0 & 0.4 & 0.0 & $0 \cdot 1$ & 0.0 & 0.330 & $<0.001$ \\
\hline Rice cakes & 0.5 & 0.0 & 0.5 & 0.1 & 0.5 & 0.1 & 0.5 & 0.2 & 0.494 & 0.776 \\
\hline Meats, fishes, eggs and legumes & 11.9 & 0.2 & $12 \cdot 1$ & 0.7 & $12 \cdot 6$ & 0.8 & 8.9 & 1.7 & 0.723 & 0.168 \\
\hline Pork and beef & 2.6 & 0.1 & 2.4 & 0.2 & 2.5 & 0.2 & 1.7 & 0.4 & 0.304 & 0.056 \\
\hline Poultry & 0.8 & 0.0 & 0.8 & 0.1 & 0.8 & 0.1 & 0.4 & 0.1 & 0.321 & $<0.001$ \\
\hline Fish and shellfish & 4.1 & 0.1 & 4.4 & 0.4 & 4.5 & 0.4 & 3.4 & 1.0 & 0.485 & 0.499 \\
\hline Eggs & 2.5 & $0 \cdot 1$ & 2.5 & 0.2 & $2 \cdot 6$ & 0.2 & 1.9 & 0.4 & 0.872 & 0.409 \\
\hline Soyabeans and soyabean products & 1.9 & 0.1 & $2 \cdot 1$ & 0.2 & $2 \cdot 2$ & 0.3 & 1.4 & 0.4 & 0.329 & 0.252 \\
\hline Vegetables & $26 \cdot 8$ & 0.3 & $23 \cdot 7$ & 0.9 & 24.0 & 0.9 & 21.6 & 1.9 & 0.001 & 0.001 \\
\hline Fresh vegetables & 4.5 & 0.1 & 3.9 & 0.2 & 4.0 & 0.2 & 3.0 & 0.5 & 0.011 & 0.017 \\
\hline Cooked vegetables & 4.0 & 0.1 & 3.4 & 0.3 & 3.4 & 0.3 & 3.1 & 0.8 & 0.010 & 0.004 \\
\hline Pickled vegetables & $17 \cdot 4$ & 0.2 & $15 \cdot 6$ & 0.6 & $15 \cdot 7$ & 0.7 & $15 \cdot 1$ & 1.5 & 0.016 & 0.046 \\
\hline Seaweeds & 3.0 & 0.1 & 2.5 & 0.2 & 2.5 & 0.3 & $2 \cdot 3$ & 0.5 & 0.010 & 0.023 \\
\hline Fruits & 7.5 & 0.2 & $5 \cdot 3$ & 0.5 & 5.6 & 0.6 & 2.8 & 0.6 & 0.001 & 0.002 \\
\hline Nuts & 0.6 & 0.0 & 0.4 & 0.1 & 0.4 & 0.1 & 0.4 & 0.1 & 0.001 & 0.005 \\
\hline Milk and milk products & 4.5 & 0.1 & 4.0 & 0.4 & 4.3 & 0.5 & 1.9 & 0.5 & $<0.001$ & $<0.001$ \\
\hline Non-alcoholic beverages & $15 \cdot 7$ & 0.3 & 13.9 & 0.8 & 13.9 & 0.8 & $14 \cdot 1$ & $2 \cdot 8$ & 0.652 & 0.052 \\
\hline Coffee & $12 \cdot 2$ & 0.3 & 11.3 & 0.7 & 11.2 & 0.7 & 11.7 & 2.5 & 0.054 & 0.133 \\
\hline Tea & 1.3 & 0.1 & 0.8 & 0.2 & 0.8 & 0.2 & 0.8 & 0.4 & 0.274 & 0.508 \\
\hline Fruit juice & 0.9 & 0.0 & 0.6 & 0.1 & 0.6 & 0.1 & 0.6 & 0.2 & 0.004 & 0.014 \\
\hline Soft drinks & 0.9 & 0.0 & 0.7 & 0.1 & 0.7 & 0.1 & 0.9 & 0.3 & 0.001 & 0.006 \\
\hline Alcoholic beverages & 1.9 & 0.1 & 1.9 & 0.3 & $2 \cdot 0$ & 0.3 & 1.4 & 0.3 & 0.065 & 0.158 \\
\hline
\end{tabular}

${ }^{\star}$ Age- and sex-adjusted means and standard errors were calculated by applying sampling weights assigned to individual participants in the nutrition survey. $\dagger P$ value for differences between food-secure adults and all food-insecure adults was calculated using multivariate linear regression after adjusting for age (continuous) and sex.

$\ddagger P$ value for differences between food-secure adults, food-insecure adults without hunger and food-insecure adults with hunger was calculated using multivariate linear regression after adjusting for age (continuous) and sex.

Table 5 Daily intakes of energy and nutrients obtained from the FFQ according to food security status among adults aged 19-64 years in the 2012 Korea National Health and Nutrition Examination Survey

\begin{tabular}{|c|c|c|c|c|c|c|c|c|c|c|}
\hline \multirow[b]{3}{*}{ Food group } & & & \multicolumn{6}{|c|}{ Food-insecure household adults } & \multirow[b]{3}{*}{$P$ value } & \multirow[b]{3}{*}{$P$ valuef } \\
\hline & \multicolumn{2}{|c|}{$\begin{array}{l}\text { Food-secure household } \\
\text { adults }(n 3480)\end{array}$} & \multicolumn{2}{|c|}{ All $(n 261)$} & \multicolumn{2}{|c|}{$\begin{array}{l}\text { Without hunger } \\
\quad(n \text { 233) } \\
\end{array}$} & \multicolumn{2}{|c|}{$\begin{array}{l}\text { With hunger } \\
(n 28)\end{array}$} & & \\
\hline & Mean* $^{*}$ & SE & Mean* $^{*}$ & SE & Mean* & SE & Mean* & SE & & \\
\hline Energy $(\mathrm{kJ} / \mathrm{d})$ & 9360 & 82 & 9117 & 305 & 9315 & 327 & 7590 & 600 & 0.444 & 0.016 \\
\hline Energy $(\mathrm{kcal} / \mathrm{d})$ & $2237 \cdot 0$ & $19 \cdot 6$ & $2179 \cdot 0$ & $72 \cdot 9$ & $2226 \cdot 4$ & $78 \cdot 2$ & $1814 \cdot 1$ & $143 \cdot 3$ & 0.444 & 0.016 \\
\hline Protein $(\mathrm{g} / \mathrm{d})$ & 63.6 & 0.3 & $60 \cdot 4$ & 0.9 & $61 \cdot 2$ & 0.9 & $54 \cdot 1$ & $2 \cdot 8$ & 0.001 & $<0.001$ \\
\hline Fat $(g / d)$ & $37 \cdot 2$ & 0.3 & 35.5 & 1.0 & 36.0 & 1.0 & $32 \cdot 0$ & $2 \cdot 7$ & 0.089 & 0.080 \\
\hline Carbohydrates (g/d) & $330 \cdot 0$ & 1.2 & 322.9 & $4 \cdot 1$ & 323.7 & 4.4 & $317 \cdot 3$ & $8 \cdot 2$ & 0.100 & 0.151 \\
\hline Crude fibre $(g / d)$ & $6 \cdot 7$ & 0.1 & $5 \cdot 6$ & 0.2 & $5 \cdot 6$ & 0.2 & $5 \cdot 1$ & 0.7 & $<0.001$ & $<0.001$ \\
\hline $\mathrm{Ca}(\mathrm{mg} / \mathrm{d})$ & $490 \cdot 6$ & $4 \cdot 2$ & $452 \cdot 6$ & $10 \cdot 6$ & 461.4 & $11 \cdot 3$ & 384.9 & $26 \cdot 6$ & 0.001 & $<0.001$ \\
\hline$P(\mathrm{mg} / \mathrm{d})$ & $1005 \cdot 7$ & $5 \cdot 0$ & 939.8 & $13 \cdot 6$ & 954.5 & $13 \cdot 8$ & $827 \cdot 0$ & $48 \cdot 2$ & $<0.001$ & $<0.001$ \\
\hline $\mathrm{Na}(\mathrm{mg} / \mathrm{d})$ & $3247 \cdot 7$ & $24 \cdot 8$ & 3074.5 & $78 \cdot 1$ & $3107 \cdot 0$ & 81.5 & $2823 \cdot 8$ & $228 \cdot 3$ & 0.027 & 0.047 \\
\hline $\mathrm{K}(\mathrm{mg} / \mathrm{d})$ & $2797 \cdot 7$ & $17 \cdot 1$ & 2469.5 & $47 \cdot 8$ & $2507 \cdot 2$ & $47 \cdot 7$ & $2178 \cdot 8$ & $168 \cdot 6$ & $<0.001$ & $<0.001$ \\
\hline $\mathrm{Fe}(\mathrm{mg} / \mathrm{d})$ & $14 \cdot 2$ & 0.1 & $13 \cdot 2$ & 0.2 & 13.4 & 0.2 & 11.9 & 0.9 & $<0.001$ & $<0.001$ \\
\hline Vitamin Á $(\mu \mathrm{g} R E / d)$ & $517 \cdot 0$ & 4.7 & $460 \cdot 5$ & $12 \cdot 6$ & $468 \cdot 4$ & $13 \cdot 0$ & $399 \cdot 6$ & $32 \cdot 2$ & $<0.001$ & $<0.001$ \\
\hline Thiamin $(\mathrm{mg} / \mathrm{d})$ & 1.90 & 0.01 & 1.77 & 0.02 & 1.79 & 0.02 & 1.65 & 0.09 & $<0.001$ & $<0.001$ \\
\hline Riboflavin (mg/d) & 1.28 & 0.01 & $1 \cdot 17$ & 0.02 & $1 \cdot 18$ & 0.03 & $1 \cdot 13$ & 0.08 & $<0.001$ & $<0.001$ \\
\hline $\operatorname{Niacin}(\mathrm{mg} / \mathrm{d})$ & $13 \cdot 0$ & $0 \cdot 1$ & $11 \cdot 8$ & 0.2 & $12 \cdot 0$ & 0.2 & $10 \cdot 7$ & 0.6 & $<0.001$ & $<0.001$ \\
\hline Vitamin $C(\mathrm{mg} / \mathrm{d})$ & $107 \cdot 2$ & 1.7 & $77 \cdot 1$ & 3.8 & $79 \cdot 3$ & 4.3 & $60 \cdot 7$ & 8.4 & $<0.001$ & $<0.001$ \\
\hline
\end{tabular}

$1 \mathrm{kcal}=4.184 \mathrm{~kJ} ; \mathrm{RE}$, retinol equivalents.

${ }^{*}$ Age- and sex-adjusted means and standard errors were calculated by applying sampling weights assigned to individual participants in the nutrition survey. $\dagger P$ value for differences between food-secure adults and all food-insecure adults was calculated using multivariate linear regression after adjusting for age (continuous) and sex.

$\ddagger P$ value for differences between food-secure adults, food-insecure adults without hunger and food-insecure adults with hunger was calculated using multivariate linear regression after adjusting for age (continuous) and sex. 


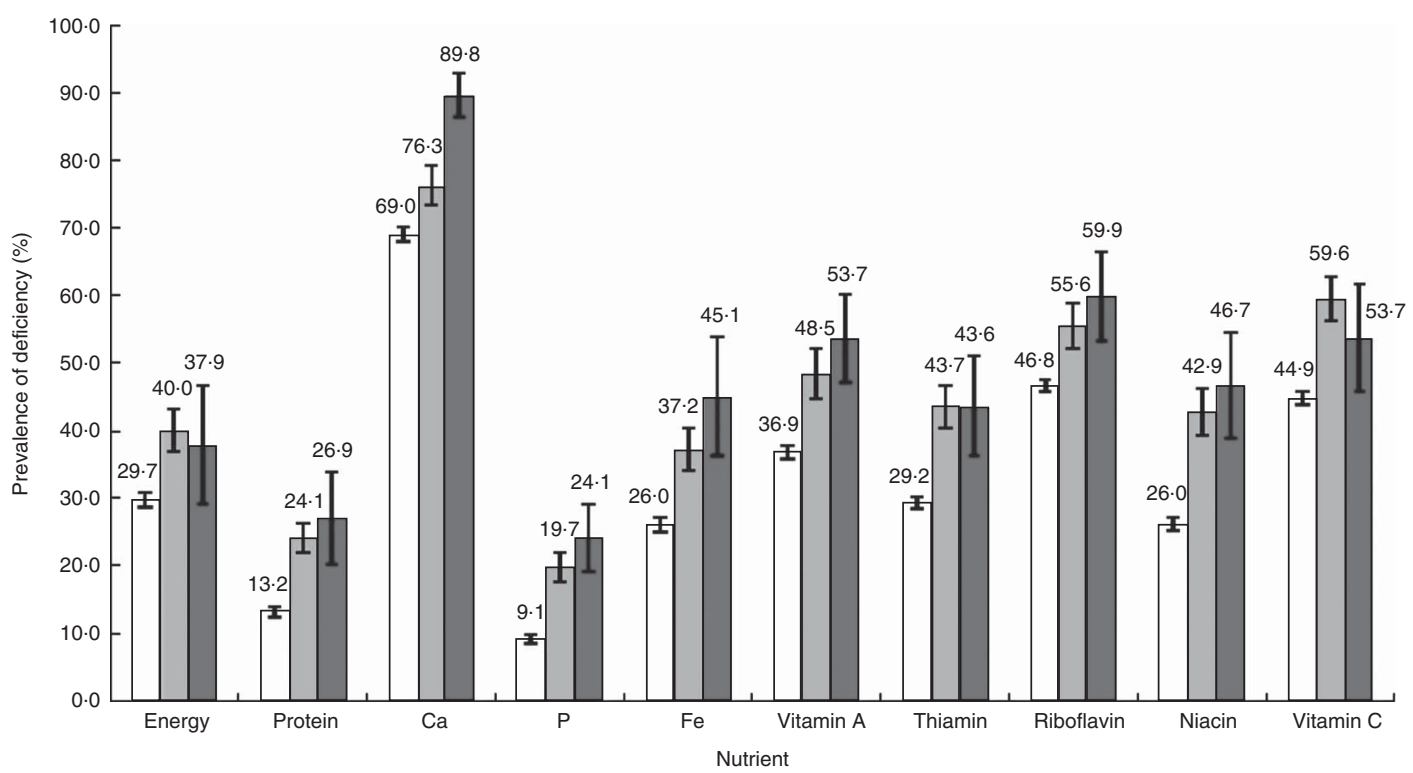

Fig. 1 Prevalence of deficient intakes of energy and nutrients compared with the Korean Dietary Reference Intake according to food security status ( $\square$, food-secure ( $n$ 6486); $\square$, food-insecure without hunger ( $n$ 546); $\square$, food-insecure with hunger ( $n$ 81)) among family members aged $\geq 1$ year who participated in a $24 \mathrm{~h}$ dietary recall survey, 2012 Korea National Health and Nutrition Examination Survey. Energy deficiency was defined as energy intake less than $75 \%$ of the estimated energy requirement according to sex and age for Koreans; nutrient deficiency was defined as nutrient intake less than the estimated average requirement according to sex and age for Koreans. Values are weighted percentages with their standard errors represented by vertical bars, which were calculated by applying sampling weights assigned to individual participants in the nutrition survey. Using the $x^{2}$ test, all $P$ values for differences in prevalence between food-secure individuals, food-insecure individuals without hunger and food-insecure individuals with hunger were $<0.01$

\section{Discussion}

Using data from the 2012 KNHANES, we estimated that the prevalence of household food security was $88.7 \%$ in a representative Korean population. We also found that the food security status of households was related to the socioeconomic status of the household and householder. The proportion of skipped meals was significantly higher in children and adults of food-insecure households. Moreover, intakes of foods (vegetables, seaweeds, fruits, fruit juice, nuts, and milk and milk products) and nutrients (protein, crude fibre, minerals and vitamins) were significantly lower in food-insecure adults compared with food-secure adults. However, intakes of energy, fat and carbohydrates were not significantly different between food-insecure and food-secure adults.

Although South Korea has experienced rapid economic growth during the past several decades, social polarization deepened after a financial crisis in $1997^{(16)}$. For this reason, concerns about food insecurity are increasing in South Korea. In the present study, the percentage of food-insecure households was $11.3 \%$ (including $2.0 \%$ for food insecurity with hunger). This is lower than the $14 \%$ of the general US population with food insecurity (including $5.7 \%$ for food insecurity with hunger) characterized using the eighteenitem $\operatorname{HFSSM}^{(17)}$. In our study, food insecurity was more prevalent among households with children (13.2\%) than among households without children (10.3\%), which is consistent with results from a national survey in the USA ${ }^{(17)}$ and Australia ${ }^{(18)}$. The Korea National Statistical Office has reported that the relative poverty rate in Korea (defined as the proportion of the population with income below $50 \%$ of the median income) was $11 \cdot 1 \%$ in households with children and $14.3 \%$ in households without children ${ }^{(19)}$. However, it has been determined that the average monthly cost of raising a child in South Korea is 1.19 million won (approximately \$US 1150) ${ }^{(20)}$. Therefore, households with children may have reduced money to purchase food. In our study, the prevalence of food insecurity was $13.5 \%$ (including $1.6 \%$ for food insecurity with hunger) among children, which exceeded the $8.2 \%$ found among adults (including $0.9 \%$ for food insecurity with hunger). The prevalence of skipping breakfast and any meals was significantly higher in food-insecure children compared with food-secure children. Using data from a $24 \mathrm{~h}$ recall, we observed that the mean intakes of energy and nutrients of young children aged 1-4 years in food-insecure households were not different from those of children in food-secure household (data not shown). This can be explained by the fact that young children aged $\leq 4$ years residing in foodinsecure households are protected from the effects of the household's food insecurity ${ }^{(21)}$. However, food-insecure children aged 5-18 years showed significantly lower intakes of protein, fat, $\mathrm{Ca}, \mathrm{P}$ and $\mathrm{K}$ compared with foodsecure children (data not shown). During childhood, inadequate dietary intake can negatively impact health and 
growth $^{(22)}$ and can lead to increased obesity and diet-related chronic diseases during adulthood ${ }^{(23,24)}$. Also, elderly individuals living in households with children demonstrated the worst food security conditions. Therefore, food assistance programmes are needed for food-insecure household with children and the elderly.

It has been suggested that food insecurity is affected by the socio-economic status of the household and householders $^{(8,17,18,25)}$. In the present study, food-insecure households showed a higher proportion of individuals living alone, lone parents or grandparent-headed families compared with food-secure households. A majority of food-insecure households had the lowest income and did not have a permanent residence. These results indicate that food insecurity is strongly associated with socio-economic status of the household. Food-insecure households were more likely to receive basic livelihood security. However, among foodinsecure households with hunger, only $27 \cdot 2 \%$ received current basic livelihood security and only $28.5 \%$ had experienced food assistance during 1 year prior to the study (Table 2). Moreover, approximately $65 \%$ did not receive either basic livelihood security or food assistance although they were in hunger (data not shown). This indicates that a strategy for selecting food-insecure households with hunger as recipients of food assistance programmes is needed.

The condition of limited access to sufficient, safe and nutritious foods can lead to inadequate dietary intake. In the present study, the weekly consumption frequencies of vegetables (fresh, cooked and pickled), seaweeds, fruits, fruit juice, nuts, and milk and milk products were significantly lower in food-insecure adults compared with food-secure adults. As income decreases, food choices usually shift from healthy foods including high-quality proteins, whole grains, vegetables and fruits to less expensive energy-dense foods ${ }^{(26)}$. Vegetables and fruits are a major source of antioxidant nutrients, fibre and phytochemicals known to contribute to a reduced risk of chronic diseases, including cancer and $\mathrm{CVD}^{(27,28)}$. Koreans often consume processed vegetables including cooked and pickled vegetables rather than fresh vegetables. Although vegetables are not considered expensive, cooking vegetables is more time consuming. Decreased vegetable intake among food-insecure adults could be attributed to the lack of affordable time to cook food or knowledge of a healthy diet. Moreover, food-insecure adults showed significantly higher consumption of processed products, such as ramen and curry rice, and inexpensive street foods (ready-to-eat foods) including tteokbokki (stir-fried rice cake with fermented red pepper paste), sundae (a kind of sausage made of pig's intestines stuffed with cellophane noodles and pork blood) and fish paste compared with food-secure adults (data not shown). Also, food-insecure adults with hunger more frequently consumed soft drinks (0.9 times/week) compared with food-insecure adults without hunger ( 0.7 times/week). Except for energy, fat and carbohydrates, the mean intakes of protein, fibre, vitamins and minerals were significantly lower in food-insecure adults compared with food-secure adults.
When stratified analysis was conducted by sex, a pattern of lower intakes of food groups and nutrients in food-insecure households was observed in both men and women, except for alcohol; food-insecure men more frequently consumed alcohol (3.1 times/week) compared with food-secure men (2.8 times/week) with significance $(P<0.001$; data not shown). Additionally, the proportions with deficient intakes of energy and nutrients compared with dietary reference intakes were higher in family members of food-insecure households. These results indicate that food insecurity is directly associated with inadequate dietary intake.

The present study has several limitations. First, there is a possibility of under-reporting because of the sensitive nature of questions regarding food insecurity. In addition, households that refused to participate or did not complete the food security survey shared similar characteristics to foodinsecure households in the study (data not shown). Moreover, the KNHANES did not include institution-dwelling individuals or people who are difficult to identify, locate or interview (e.g. homeless individuals). This indicates that the prevalence of household food insecurity could be underestimated. Second, we applied the status of household food security to individuals, although there is a possibility that food security of family members was not directly affected by the status of household food insecurity. Third, there were no data from FFQ for children and the elderly. However, the results from a $24 \mathrm{~h}$ recall were similar with those from the FFQ among adults having both data; using data from a $24 \mathrm{~h}$ recall, daily intakes of most nutrients, except for energy, carbohydrates, $\mathrm{Na}$ and vitamin $\mathrm{A}$, showed significant differences between the food-secure adults and foodinsecure adults (data not shown). Despite these limitations, our study is the first nationwide survey to evaluate the prevalence of household food insecurity and compare dietary intake by food security status using a validated food security questionnaire in a representative Korean population.

\section{Conclusion}

Our results revealed that food-insecure people consumed significantly less healthy foods and nutrients essentially needed for health and growth. Inequality in the accessibility to and availability of various foods could contribute to health inequalities through inadequate nutritional status $^{(29)}$. Therefore, development of a good approach for identifying food-insecure households with hunger and implementation of enhanced food assistance programmes are required for food-insecure households in Korea.

\section{Acknowledgements}

Financial support: The KNHANES was financially supported by the Health Promotion Fund with administrative 
support by the Ministry of Health and Welfare. The Health Promotion Fund and the Ministry of Health and Welfare had no role in the design, analysis or writing of this article. Conflict of interest: None. Authorship: H.J.K. contributed to the analysis and interpretation of data and writing the article. K.O. participated in the design of study, acquisition of data, and analysis and interpretation of data. Ethics of buman subject participation: The institutional review board of the Korea Centers for Disease Control and Prevention approved all procedures and protocols used in the study (2012-01EXP-01-2C). Written informed consent regarding the survey was obtained from all participants.

\section{References}

1. Anderson SA (1990) Core indicators of nutritional state for difficult-to-sample populations. J Nutr 120, Suppl. 11, $1559-1600$

2. Kim S, Moon S \& Popkin BM (2000) The nutrition transition in South Korea. Am J Clin Nutr 71, 44-53.

3. Hong SA, Kim K \& Kim MK (2012) Trends in the inequality of fruit and vegetable consumption between education levels indicated by the Korea National Health and Nutrition Examination Surveys. Eur J Clin Nutr 66, 942-949.

4. Darmon N \& Drewnowski A (2008) Does social class predict diet quality? Am J Clin Nutr 87, 1107-1117.

5. Oh SY \& Hong MJ (2003) Food insecurity is associated with dietary intake and body size of Korean children from low-income families in urban areas. Eur J Clin Nutr 57, 1598-1604.

6. Kim K \& Kim MK (2009) Development and validation of food security measures. Korean J Nutr 42, 374-385.

7. Kim K, Hong SA, Kwon SO et al. (2011) Validation of food security measures for the Korean National Health and Nutrition Examination Survey. Korean J Community Nutr 16, 771-781.

8. Kim K, Kim MK, Shin YJ et al. (2011) Factors related to household food insecurity in the Republic of Korea. Public Health Nutr 14, 1080-1087.

9. Yun SH, Shim JS, Kweon S et al. (2013) Development of a food frequency questionnaire for the Korea National Health and Nutrition Examination Survey: data from the Fourth Korea National Health and Nutrition Examination Survey. Korean J Nutr 46, 186-196.

10. Rural Resources Development Institute (2006) Food Composition Table (7th Revision). Suwon, Korea: Rural Resources Development Institute.

11. Rural Resources Development Institute (2011) Food Composition Table (8th Revision). Suwon, Korea: Rural Resources Development Institute.

12. Kim DW, Song S, Lee JE et al. (2014) Reproducibility and validity of an FFQ developed for the Korea National Health and Nutrition Examination Survey (KNHANES). Public Health Nutr (Epublication ahead of print version).

13. Korean Nutrition Society (2010) Dietary Reference Intakes for Koreans. Seoul: Korean Nutrition Society.

14. Kim K, Hong SA, Kwon SO et al. (2011) Development of food security measures for the Korean National Health and Nutrition Examination Survey. Korean J Nutr $\mathbf{4 4}$, 551-561.

15. Willett WC (2013) Nutritional Epidemiology, 3rd ed. New York: Oxford University Press.

16. Kang SW, Shin YS, Lee TJ et al. (2006) A Study on Social Polarization in Korea. Seoul: Korea Institute for Health and Social Affairs.

17. Coleman-Jensen A, Nord M \& Singh A (2013) Household Food Security in the United States in 2012. Washington, DC: US Department of Agriculture.

18. Babbington S \& Donato-Hunt C (2007) When There Isn't Enough To Eat. The Food Security of ANGLICARE Sydney's Emergency Relief Clients in Wollongong: Full Report of the Pilot Study. Farramatta, NSW: Policy Unit of ANGLICARE, Diocese of Sydney.

19. Korea National Statistical Office (2013) Survey of Household Finances and Living Conditions. Daejeon, Korea: Korea National Statistical Office.

20. Kim SG, Kim YK, Kim HR et al. (2012) The 2012 National Survey on Fertility, Family Health and Welfare in Korea. Seoul: Korea Institute for Health and Social Affairs.

21. Coleman-Jensen A, Nord M \& Singh A (2013) Food Insecurity in Households with Children: Prevalence, Severity, and Housebold Characteristics, 2010-11. Washington, DC: US Department of Agriculture.

22. Cook JT \& Frank DA (2008) Food security, poverty, and human development in the United States. Ann N Y Acad Sci 1136, 193-209.

23. Ness AR, Maynard M, Frankel S et al. (2005) Diet in childhood and adult cardiovascular and all cause mortality: the Boyd Orr cohort. Heart 91, 894-898.

24. Power C \& Parsons T (2000) Nutritional and other influences in childhood as predictors of adult obesity. Proc Nutr Soc 59, 267-272.

25. Temple JB (2008) Severe and moderate forms of food insecurity in Australia: are they distinguishable? Aust J Soc Issues $\mathbf{4 3}, 649$.

26. Drewnowski A \& Eichelsdoerfer P (2010) Can lowincome Americans afford a healthy diet? Nutr Today $\mathbf{4 4}$, 246-249.

27. World Cancer Research Fund/American Institute for Cancer Research (2007) Food, Nutrition, Physical Activity, and the Prevention of Cancer: A Global Perspective. Washington, DC: AICR.

28. Wang X, Ouyang Y, Liu J et al. (2014) Fruit and vegetable consumption and mortality from all causes, cardiovascular disease, and cancer: systematic review and dose-response meta-analysis of prospective cohort studies. BMJ 349, g4490.

29. Campbell CC (1991) Food insecurity: a nutritional outcome or a predictor variable? J Nutr 121, 408-415. 